\title{
Comparing ELECTRE and Linear Assignment Methods in Zoning Shahroud-Bastam Watershed for Artificial Recharge of Groundwater with GIS Technique
}

\author{
Azam Abdolazimi ${ }^{1}$, Mehdi Momeni ${ }^{1} \&$ Majid Montazeri $^{2}$ \\ ${ }^{1}$ Faculty of Humanities, Najafabad Branch, Islamic Azad University, Najafabad, Isfahan, Iran \\ ${ }^{2}$ Assistant Professor of Climatology, University of Isfahan, Isfahan, Iran \\ Correspondence: Azam Abdolazimi, Faculty of Humanities, Najafabad Branch, Islamic Azad University, \\ Najafabad, Isfahan, Iran. E-mail: azamabdolazimi@yahoo.com; saba221azam@gmail.com
}

Received: September 21, 2014

Accepted: September 30, 2014

Online Published: November 23, 2014

doi:10.5539/mas.v9n1p68

URL: http://dx.doi.org/10.5539/mas.v9n1p68

\begin{abstract}
Today, uncontrolled exploitation of ground water has doubled water scarcity problem, while proper control and management of these resources can solve water shortage problem to some extent. One of the approaches for managing groundwater resources is artificial recharging of groundwater and determining the best location for this. This study aimed at ranking Shahroud-Bastam watershed using ELECTRE and linear assignment methods and the results of these two methods are compared. These two models are of multiple-criteria decision making compensation and coordinated subgroup models. The findings indicate that among the seven zones in ELECTRE method mentioned above, zones $(3,4,5)$ with four dominations and 2 defeats and 2 points are in the first ranking and are the most suitable zones for artificial recharge. Zone (1) with six defeats and no dominations and (-6) points is in the last ranking and is not suitable for artificial recharge of ground water. Zones $(2,6,7)$ respectively with $(2,2,1)$ dominations and $(4,4,5)$ defeats and with $(-2,-2,-4)$ points are in the next rankings respectively. Zones $(1,2,6,7)$ must be removed because the number of their defeats is more than the number of their dominations and have negative points. In linear assignment method, among 7 zones, zone 3 has the first rank and is the best zone for artificial recharge and zone 7 is in the last ranking and is not suitable for artificial recharge. Zones $(4,2,5,6,1)$ are in the next rankings respectively. Between these two methods, the results of linear assignment method are more consistent with reality and are more accurate.
\end{abstract}

Keywords: watershed, Shahrood-Bastam, ELECTRE method, linear assignment method, GIS technique, zoning

\section{Introduction}

Recently, with the increasing growth of population, industry development, urbanization growth, and consequently the increase in demand for food, exploitation of water resources is several times higher than the past so that the exploitation of groundwater resources is greater than their recharge rate. In other words, the input of ground water system has become less than its output and the system with negative balance has positive feedback and is in the process of degradation and dissolution. Therefore, the identification of the most suitable place for this purpose is very important. Groundwater sources are the largest reservoir of sweet water after glaciers and ice sheets and are one of the most important sources of providing sweet water needed by humans (Freezer, 1979). The necessity for identification and optimal utilization of groundwater resources stems from the fact that these resources constitute $99 \%$ of all available sweet water (Kowsar, 2005, 19). In addition, these resources form more than 80 percent of water used in many countries located in arid and semi-arid areas (Sedaghat, 1993). Due to the fact that Iran is located in arid and semi-arid area and the mean of annual precipitation is $250 \mathrm{~mm}$, so in many parts of the country, it has always been tried to provide water for various uses for agriculture, industry and drinking. Shahrood province with 234,738 people with an area of 51,762 km (Iran National Portal of Statistics, 2006) is the largest population center in Semnan province which has had a significant increasing trend in recent years. More than $50 \%$ of the required water resources of the province are supplied by groundwater in Shahrood-Bastam plain with an area of 25/7603 km. Regarding the point that Shahrood-Bastam plain is the trifocal population center of Shahrood, Bastam, and Majan which constitutes $85 \%$ of the total population of the province; therefore, identification of the best place for artificial recharge of 
groundwater aquifers in the plain and zoning it is of high importance. Water resources management is a set of several managerial measures taken aimed at optimal utilization of water resources and reduction of economic, social, and environmental losses. Decision making issues about water resources management are complex since there are multiple criteria, and criteria in decision making. To achieve a specific goal, there are several solutions, each with different preferences for different issues such as environmental, social, political, and organizational issues. These requirements naturally lead to the use of Multi-Criteria Decision-Making methods (MCDM) which aims to choose the best answer from among several solutions. Numerous studies have been carries out on artificial recharge of ground water, as well as multi-criteria approaches. Krishnomurthy et al. (1995 \& 1996) used RS and GIS techniques for locating suitable areas for artificial recharge of groundwater in India and studied the geological and geomorphological factors in groundwater behavior and stated that certain roughness in each region is suitable for groundwater recharge.

Saraf \& Choudhury (1998) used remote assessing capabilities to extract different layers such as land use, geology, geomorphology, vegetation, and their integration in a GIS environment to determine suitable areas for artificial recharge of groundwater. Mahdavi $(1996,16)$ studied water management and artificial recharge of ground water aquifers in Jahrom province and suggested controlling using and recharging aquifers through basin and watershed management as the most important managerial solution. Abdi and Ghayoomian $(2000,86)$ prioritized appropriate locations for the storage of surface water and groundwater strengthening according to geophysical data, topography and land use and their integration and analysis in GIS.

Kia Heyrati (2003) studied the functioning of floodwater spreading system in recharging ground water aquifers in Moghar Plain in Isfahan. Mahdavi et al. (2004) studied finding the suitable sites for artificial recharge of ground water through the RS and GIS in the watershed of Shahreza and introduced it as an efficient tool for this purpose.

Noori et al. $(2004,635)$ studied suitable areas for artificial recharge of groundwater in the form of recharge ponds and using GIS technique in Gavbandy watershed and suggested that the best place for artificial recharge are alluvial fans and Dashtsar. Mousavi et al. (2009) studied finding the potential suitable areas for artificial recharge of groundwater within the Kamestan anticline by the integration of remote assessing and GIS and suggested that fractured formations, alluviums and fluvial channels are the most suitable locations for artificial recharge. Mianabadi and Afshar (2008) used the three ways of Inductive Ordered Weighted Averaging (IOWA), linear assignment, and TOPSIS to evaluate and rank projects of urban water supply in Zahedan and compared the results of different methods with the results of adaptive planning method (Mianabadi, 2008:34-45).

Limon and Martinez (2006) utilized Multi-Attribute Utility Theory (MAUT) for optimal allocation of water for agriculture in the north of Spain (Limon, 2006: 313-336). Ahmadi et al. (2002) ranked various projects for agricultural water filtration or refinement for reusing by multi-criteria decision-making methods (Ahmadi, 2002: 339-352). Anand Raj and Kumar (1996) used ELECTRE for ranking options or alternatives for the management of river watershed. This study aims at using ELECTRE and linear assignment methods for ranking Shahrood-Bastam watershed and the results of the two methods are compared.

\section{Materials and Methods}

\subsection{The Mathematical Location of the Studied Area}

The studied area in this research is Shahrood-Bastam watershed which is located in the north of Shahrood city in Semnan province in the southern and southeast hillsides of East Alborz. Shahrood-Bastam watershed is located under Salt Desert watershed (7/4h). Salt Desert with an area of $224370 \mathrm{~km}$ is below Central Iran watershed (4h). Central Iran watershed is a vast land of $831000 \mathrm{~km}^{2}$. The characteristic of this watershed is the minimum development of stream networks due to high dryness (Movahed Danesh, 2004, 183). Shahrood-Bastam watershed with an area of $25 / 7603 \mathrm{~km}^{2}$ has spreaded with the latitude of $36^{\circ}$ to $37^{\circ}$ north and the longitude of $54^{\circ}$ to $57^{\circ}$ east (Figure 1 ). 


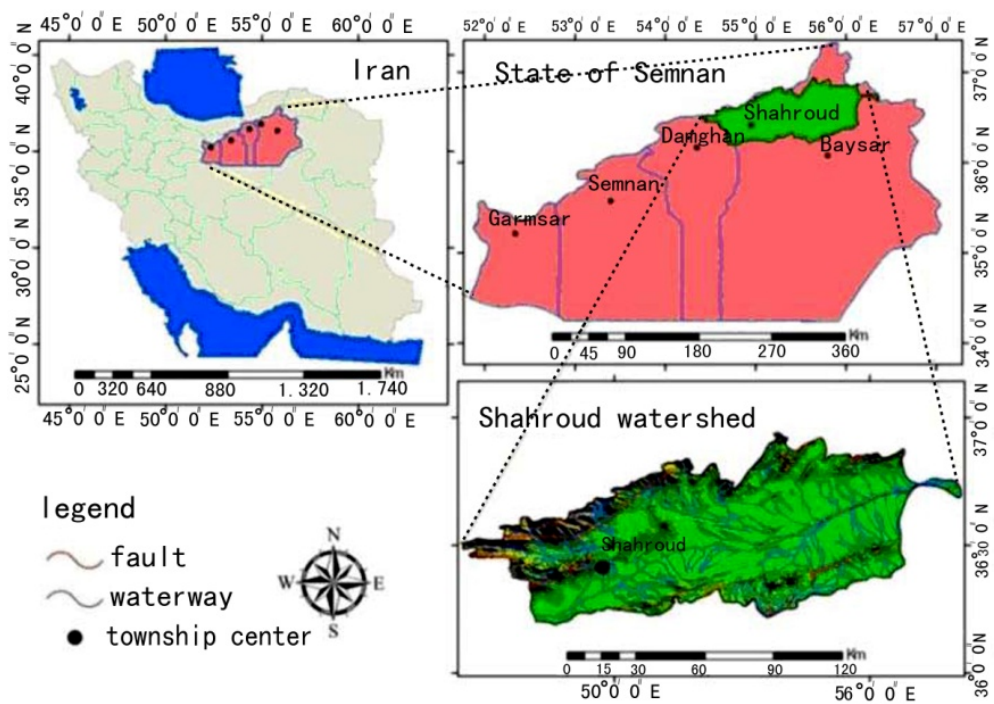

Figure 1. The mathematical location of the studied area

First, the studied area was examined using satellite images of Google Earth and the limits were demarcated. Then, its digital elevation model was separated from Iran digital elevation model by the GLOBAL MAPER software and the output was obtained. Preparation of the data layers required for zoning in Arc GIS 9.3 software was performed as follows:

The digital elevation model of the region was categorized into 7 altitude classes based on natural breaks at the heights of the region (Figure 4). The classes represent zones studied in the area and the following calculations were performed in each of these categories. Gradient or slope layer was prepared by digital elevation model of the area and Surface Analyses and 3D analyses instruments. The drainage density layer was provided by digitization of major and minor stream layers on 1:50000 topographic maps of the region and the fault density was obtained from digitization of major and minor faults on the 1:100,000 geological map of the area and Density tools in Spatial Analyses. The layer of precipitation curves alignment was obtained using Kriging interpolation method and the linear relationship between rainfall- elevation/altitude using the Interpolate tool in 3D analyses (Figures 3 to 16). Then, the studied criteria were calculated for each of the altitude zones (Tables 2 and 12) and the layers were prepared separately. After obtaining quantitative values, these numbers were analyzed using the two methods of ELECTER and linear assignment and the areas were ranked and then the results of these two methods were compared. In the past decades, the necessity of multi-criteria decision making in water resources management, decision making about water management issues and selecting the best choice among the proposed alternatives for solving the problems of a watershed were done only based on economic criteria -the ratio of benefit to cost- and transforming environmental, and social criteria to economic criteria. However, nowadays, using multi-criteria decision making methods, it is not necessary to use financial equivalents of environmental and social criteria for selecting the superior alternative, but it is possible to apply different qualitative and quantitative criteria for prioritization and selection of the best options in the management of water resources. Decision making issues and problems of water resources are often defined by a large number of alternatives and options and indeterminate outcomes, different participants with different objectives, and complex interactions and relationships. The complexity of water resources management issues on one hand and its direct relationship with other sciences on the other hand make it impossible for a decision maker to consider all aspects required for comprehensive management and planning of water resources on his own. Therefore, it is essential that several decision makers with several different expertise and skills such as agriculture, economy, environment, etc. are used in the decision process about water resources (Afshar, 2007, 3-11). Considering all the above indicate the importance and necessity of applying multi-criteria decision making models in Integrated Water Resource Management (IWRM). Theoretical bases of ELECTER and linear assignment methods and multi-criteria decision making models (MCDM) have drawn the attention of many researchers for complex decision makings in recent decades. These decision making models are divided into two major categories: Multi-Objective Decision Making (MODM) and Multi-Attribute Decision Making (MADM) models so that multi-attribute models are used for selecting the best options.

Evaluation models for an MADM are divided into two compensatory and non-compensatory models. 
Non-compensatory model includes methods which often do not require information from the DM and lead to an objective response. In the compensatory model, the exchange among criteria is allowed, i.e. for example the shortcoming or weakness of an criterion may be the point of another criterion or attribute. ELECTER method is one of the available methods in compensatory models. In this method, all the options are assessed using "non-ranking' comparisons. All the stages of this process in this method are based on a coordinated set and a non-coordinated set; therefore, it is known as "Analysis of coordination".

The ELECTER method was provided by Banayoun and then developed by Van Delft, Nijkamp, Roy, and other colleagues. In ELECTER method, the concept of dominance is implicitly used. In this method, options or alternatives are compared pairwise and the dominant and weak options are identified and then the weak or defeated options are removed (Roy, 1991, 49-73).

Linear assignment method is one of multi-criteria decision-making methods, which helps decision makers to select the best choice by combining quantitative and qualitative criteria and the appropriate weighting of each criterion based on its importance. In this method, the assumed alternatives or options of a given problem are ranked based on their points of each existing criterion and final ranking of options will be determined through Linear Compensatory Process. The position of these two models among multi-criteria decision-making methods is shown in Figure 2. The resolution process is done in a way that there is no need to descale qualitative and quantitative criteria.

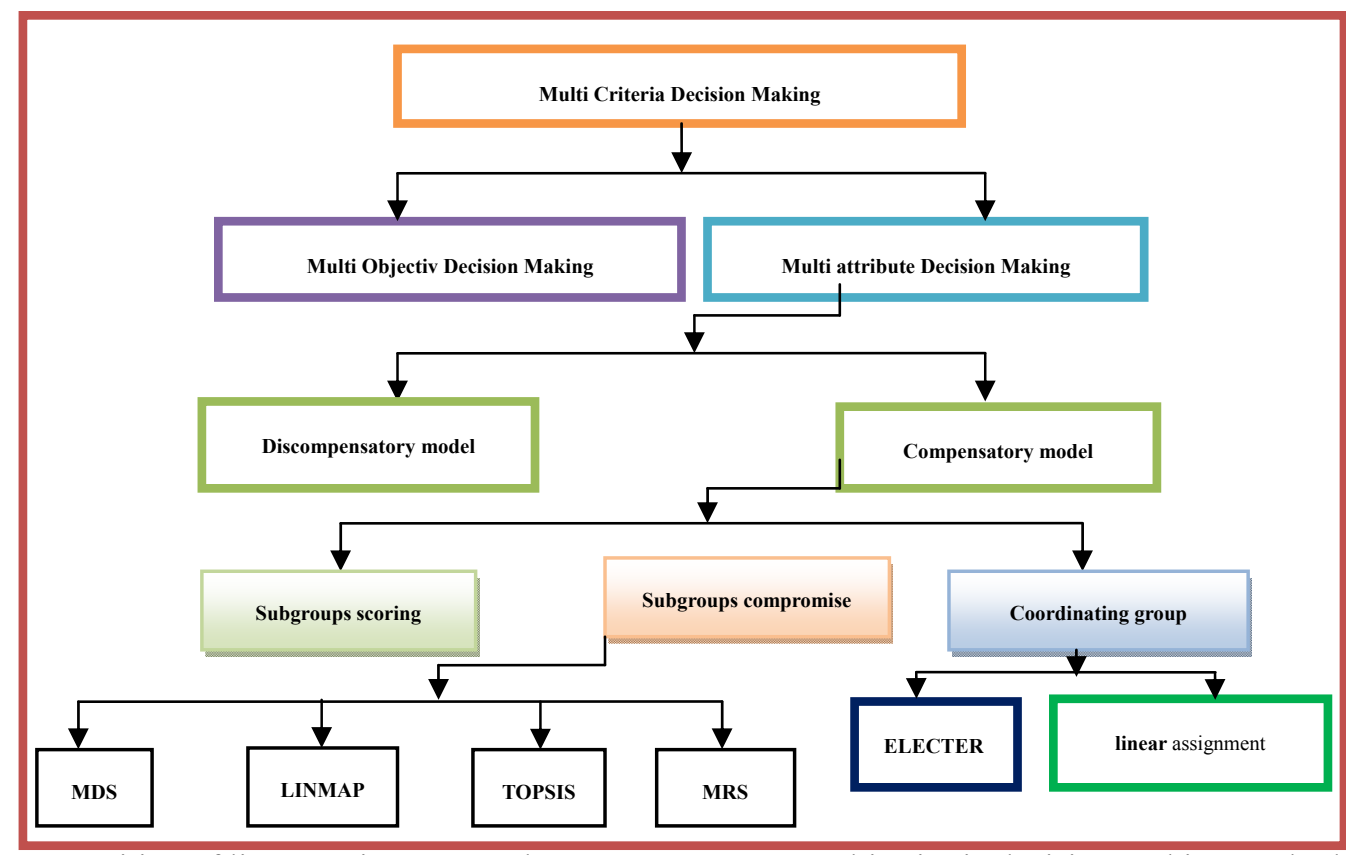

Figure 2. Position of linear assignment and ELECTER among multi-criteria decision-making methods

\section{A-The stages of problem solving be ELECTRE method}

\section{1-Forming decision matrix}

According to the criteria and the number of choices and options, and the evaluation of all options for different criteria, decision matrix is formed as follows:

$$
X=\left[\begin{array}{ccc}
x_{11} & \ldots & x_{1 n} \\
\vdots & \ldots & \ldots \\
x_{1 m} & \ldots & x_{m n}
\end{array}\right]
$$

where $\mathrm{Xij}$ is the performance or functioning of option $\mathrm{i}^{\text {th }}(\mathrm{i}=1,2, \ldots \ldots ., \mathrm{m})$ in relation to criteria $\mathrm{j}^{\text {th }}(\mathrm{j}=$ $1,2,3$, , n).

\section{2-Descaling decision matrix}

At this stage, it is tried to convert criteria with different dimensions or aspects to dimensionless criteria and the matrix $\mathrm{R}$ is defined as follows. There are various methods for making criteria dimensionless, but in ELECTRE 
method in the following equation is commonly used (Tille, 2003, 19-21). Equation (1):

$$
R=\left[\begin{array}{ccc}
r_{11} & \ldots & r_{1 n} \\
\vdots & \ldots & \ldots \\
r_{m 1} & \ldots & r_{m n}
\end{array}\right] \quad r_{i j}=\frac{x_{i j}}{\sqrt{\sum_{i=1}^{m} x_{i j}^{2}}}
$$

\section{3-Determining the matrix of the weights of criteria}

$$
W=\left[\begin{array}{ccc}
w_{1} & \ldots & 0 \\
\vdots & w_{2} & \ldots \\
0 & \ldots & w_{n}
\end{array}\right]
$$

As it can be seen, the matrix $\mathrm{W}$ is a diagonal matrix, in which only the elements on its main diagonal are not zero and the value of these elements is equal to the importance coefficient of the corresponding vector.

\section{4-Determining the weighted normalized decision matrix}

Weighted decision matrix is obtained from descaled decision matrix multiplied by the matrix of the weights of criteria.

$$
V=R \times W=\left[\begin{array}{ccc}
v_{11} & \ldots & v_{1 n} \\
\vdots & \ldots & \ldots \\
v_{m 1} & \ldots & v_{m n}
\end{array}\right]
$$

\section{5-Establishing a set of agreement and against criteria}

For each pair of options of $\mathrm{e}$, and $\mathrm{k}(\mathrm{k}, \mathrm{e}=1,2, \ldots ., \mathrm{m}, \mathrm{k} \# \mathrm{e})$, the set of criteria $\mathrm{J}=(1,2, \ldots \ldots, \mathrm{m})$ is divided into two agreement and against or opposing categories or sub-set: The agreement set (SKe) is a set of criteria in which option $\mathrm{K}$ is preferred to option e, and its complementary set is the against set (IKe), Mathematically, Equation (2) and (3):

$$
\begin{gathered}
S_{k e}=\left\{j \mid v_{k j} \geq v_{e j}\right\} \\
I_{k e}=\left\{j \mid v_{k j} \prec v_{e j}\right\}
\end{gathered}
$$

\section{6-Forming the agreement matrix}

In order to form the agreement matrix, its elements of the agreement which are called cooperation criteria should be calculated. The agreement criteria are obtained by the sum of the weights of criteria which are in agreement in total. Therefore, this cooperation criteria $\mathrm{C}_{\mathrm{ke}}$ is between the options $\mathrm{k}$ and $\mathrm{e}$ is equal to, Equation (4):

$$
c_{k e}=\frac{\sum_{j \in s_{h e}} W_{j}}{\sum_{j=1} W_{j}}
$$

For the sum of normalized weights $\sum_{j \in 1} W_{j}$ is equal to 1; therefore, Equation (5):

$$
c_{k e}=\sum_{j \in s_{k e}} W_{j}
$$

The cooperation criteria indicate the degree of the predominance or preference of option $\mathrm{k}$ to option $\mathrm{e}$ and its value varies from 0 to 1 . By calculating cooperation criteria for all options, the agreement matrix which is an $\mathrm{m}$ * $\mathrm{m}$ matrix is defined as follows, in general, this matrix is not symmetric:

$$
C=\left[\begin{array}{cccc}
- & c_{12} & \ldots & c_{1 m} \\
c_{21} & - & \ldots & c_{2 m} \\
\vdots & \vdots & - & \vdots \\
c_{m 1} & \cdots & c_{m(m-1)} & -
\end{array}\right]
$$

\section{7-Determining the disagreement matrix}

Disagreement Criterion (opposite) is defined as follows (Roy, 1991, 49-73). Equation (6): 


$$
d_{k e}=\frac{\max _{j \in I_{k e}}\left|v_{k j}-v_{e j}\right|}{\max _{j \in J}\left|v_{k j}-v_{e j}\right|}
$$

Disagreement criterion (opposite) varies from zero to one. By calculating disagreement criterion for all pair of options, the disagreement matrix which is an $\mathrm{m} * \mathrm{~m}$ matrix is defined as follows, in general, this matrix is not symmetric:

$$
D=\left[\begin{array}{cccc}
- & d_{12} & \ldots & d_{1 m} \\
d_{21} & - & \ldots & d_{2 m} \\
\vdots & \vdots & - & \vdots \\
d_{m 1} & \ldots & d_{m(m-1)} & -
\end{array}\right]
$$

It should be noted that the information and data contained in the agreement matrix varies significantly from the data in the disagreement matrix and there are considerable differences between them. In fact, these data are complementary. The differences between weights are achieved through agreement matrix, while the differences between determined values are obtained by the disagreement matrix.

\section{8- Forming agreement dominance matrix}

In the sixth stage, computing the criterion of agreement $C_{k e}$ was expressed. At this stage, a certain amount is determined for agreement criterion which is called agreement threshold and is shown by $\bar{c}$. If $C_{\mathrm{ke}}$ is larger than $\bar{c}$, the superiority or dominance of alternative $\mathrm{k}$ to alternative $\mathrm{e}$ is acceptable, otherwise the option $\mathrm{k}$ is not superior to the option e. The value of agreement threshold is calculated by the following equation (Roy, 1991, 49-73). Equation (7):

$$
\bar{c}=\sum_{\substack{k=1 \\ k \neq e=1}}^{m} \sum_{\substack{e=k \\ k \neq k}}^{m} \frac{c_{k e}}{m(m-1)}
$$

Agreement dominance matrix $(\mathrm{F})$ is formed according to the value of agreement threshold whose members are determined by the following equation (Vami, 1992). Equation (8):

\section{9-Forming disagreement dominance matrix}

$$
f_{k e}= \begin{cases}0 & c_{k e} \geq \bar{c} \\ 1 & c_{k e}<\bar{c}\end{cases}
$$

Disagreement dominance matrix $(\mathrm{G})$ is formed like agreement dominance matrix. For this purpose, first the disagreement threshold $\bar{d}$ should be expressed by decision makers which can be, e.g., the mean of disagreement (opposition) criteria (Roy, 1991, 49-73). Equation (9):

$$
\bar{d}=\sum_{\substack{k=1 \\ k \neq e=1}}^{m} \sum_{\substack{e=1 \\ \neq}}^{m} \frac{d_{k e}}{m(m-1)}
$$

As mentioned in the seventh stage, the less the disagreement criterion $\left(\mathrm{d}_{\mathrm{ke}}\right)$ the better, because the disagreement degree indicates the superiority of option $\mathrm{k}$ to option e. If $\mathrm{D}_{\mathrm{ke}}$ is larger than $\bar{d}$, the degree of disagreement is high and not negligible; as a result, the matrix of the elements of disagreement dominance $(G)$ is calculated as follows (Roy, 1991, 49-73). Equation (10):

$$
g_{k e}= \begin{cases}0 & d_{k e} \geq \bar{d} \\ 1 & d_{k e}<\bar{d}\end{cases}
$$

Each member of the matrix $(\mathrm{G})$ indicates the dominance relationship between alternatives.

\section{0- Forming the final dominance matrix}


The final dominance matrix $\mathrm{H}$ is obtained by the multiplication of every elements of agreement dominance matrix F by on the disagreement dominance matrix G (Roy, 1991, 49-73). Equation (11):

$$
h_{k e}=f_{k e} \cdot g_{k e}
$$

\section{1-Removing the options with less satisfaction and selecting the best option}

The final dominance matrix $\mathrm{H}$ expresses the little or trivial preferences of options. For example, if the value of $\mathrm{h}_{\mathrm{ke}}$ is equal to 1 , it means that the superiority or dominance of option $\mathrm{k}$ to option e is acceptable in both agreement and disagreement situations, that is, its superiority is greater than agreement threshold and its disagreement or weakness is lower than the disagreement threshold, but the option $\mathrm{k}$ has still the chance to be dominated by other options. The option should be selected which has more dominance rather being defeated and therefore the options can be ranked. For determining the significance coefficient of criteria in relation to each other, first criteria are compared pairwise according to the method recommended by Saaty.

Table 1. Weighing criteria based on preferences in pairwise form (Ghodsipoor, 2008, 14)

\begin{tabular}{cc}
\hline $\begin{array}{c}\text { Numerical } \\
\text { Number }\end{array}$ & Preferences (oral judgments) \\
\hline 9 & Extremely preferred \\
7 & Very strongly preferred \\
5 & Strongly preferred \\
3 & Moderately referred \\
1 & Equally preferred \\
$2,4,6,8$ & Preferences between strong intervals \\
\hline
\end{tabular}

After the formation of pair-wise comparison matrix, the relative weight of criteria can be calculated. There are different methods to calculate the relative weights based on pairwise comparison matrix. The most important ones are " least square method, the least square logarithmic method, specific vector method and the approximate method. Among these methods, specific vector method is more accurate than others. In this method, $\mathrm{w}_{\mathrm{i}}$ is defined in such a way that equation 12 is established. Equation (12):

\section{$\mathrm{A} \times \mathrm{W}=\lambda \max \mathrm{W}$}

Where $\lambda$ and $\mathrm{W}$ are respectively the specific values and specific vector of pair-wise comparison matrix (A). While the dimensions of the matrix are larger, calculating these values are time-consuming. Therefore, to calculate the value of $\lambda$, the values of terminal matrix $\lambda \mathrm{IA}$ is set equal to zero and by placing the largest $\lambda$ value in equation (13), the values of $\mathrm{w}_{\mathrm{i}}$ are obtained (Saaty, 2001:315). Equation (13):

$$
\mathrm{A}-\lambda_{\max } \mathrm{I}=0
$$

\section{B- The stages of problem solving by linear assignment method}

\section{1-Forming decision matrix}

First, the decision matrix is formed given the limited data obtained from the criteria in each region.

\section{2- Ranking alternatives on the basis of existing criteria}

At this stage, the regions are ranked based on the rank given to them by the criteria.

3- In the third stage, matrix QG is obtained by specifying the weights of criteria (W). Each element of the QG matrix is equal to: Equation (14)

$$
q / i t=\sum_{j=1}^{n} \pi i t j \cdot w j
$$

If option $i$ is in the ranking $t$ in the criterion $j$, then $\pi i t j=1$.

4-The following assignment problem with the variables zero-one hit is solved in order to determine the final priorities of alternatives.

$$
\text { Equation (15) } \max : \sum_{i=1}^{m} \sum_{k=1}^{m} \gamma_{i k} \cdot h_{i k}
$$




$$
\begin{gathered}
\text { s.t }: \sum_{k=1}^{m} h_{i k}=1 ; i=1,2, \ldots, m \\
\text { Equation (16): } \sum_{i=1}^{m} h_{i k}=1 ; k=1,2, \ldots, m \\
h_{i k}\left\{\begin{array}{l}
=1 \\
=0
\end{array}\right.
\end{gathered}
$$

\section{5-Ranking alternatives}

The final step is to rank the options or alternatives.

\section{Research Findings}

The results of linear assignment model for locating the most suitable areas for artificial recharge of groundwater aquifers of Shahrood-Bastam watershed are as described in Figures (3) to (9) and Tables (3) to (12) so that a matrix with the ranking 49 with 7 alternatives (high altitude zones) and 7 corresponding criteria (precipitation, stream density, fault density, area, the land side views of the area, slope, elevation) is formed for data matrix (Table 1).

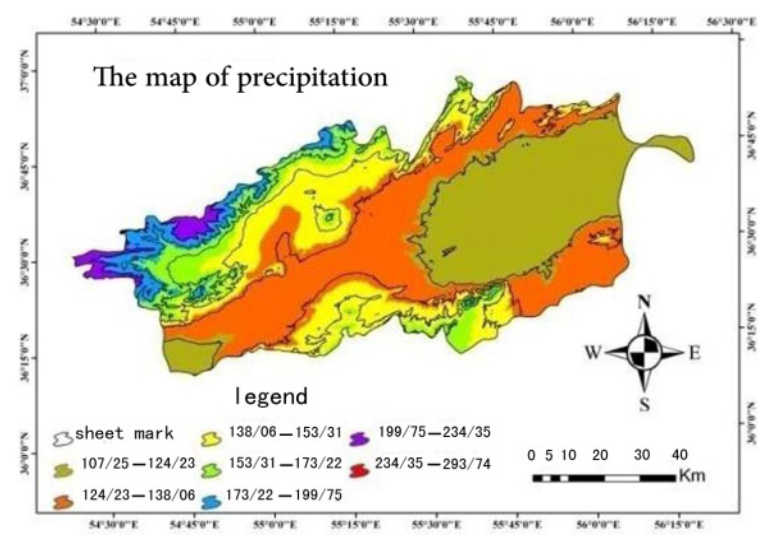

Figure 3. Map of precipitation curves alignment in the studies area

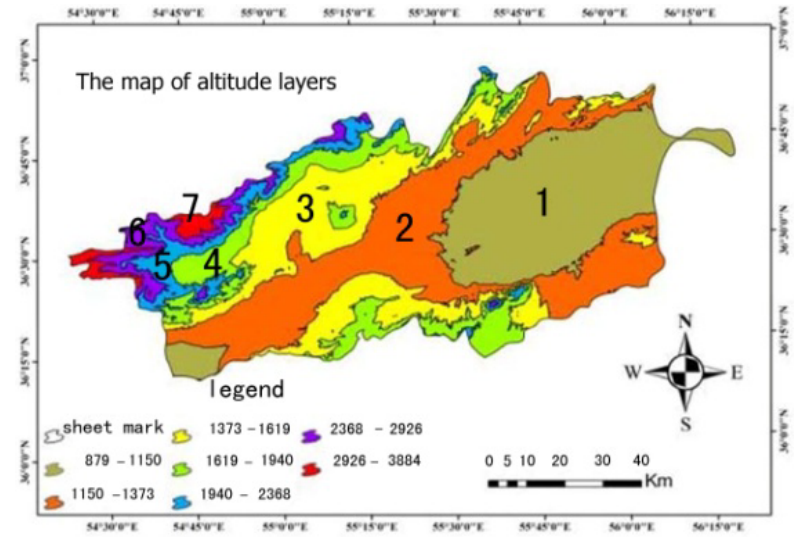

Figure 4. Map of altitude layers and zones of the studies area

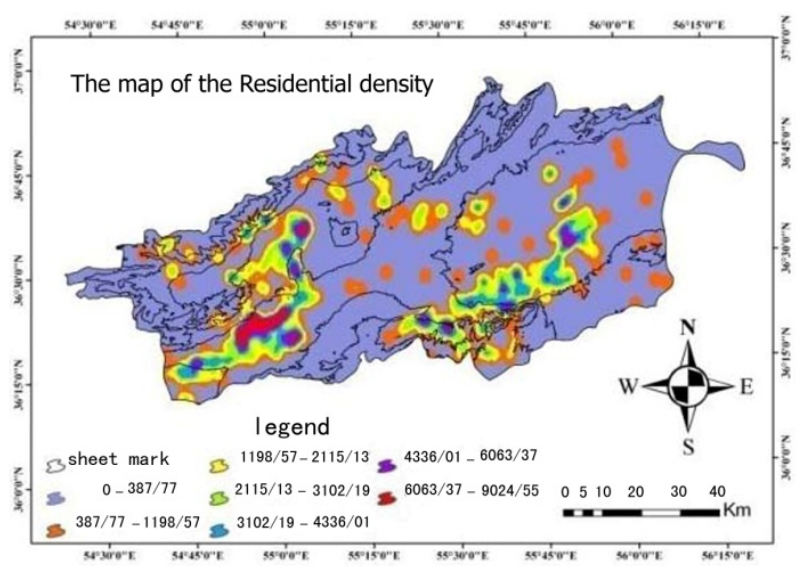

Figure 5. Residential density of the studied area 


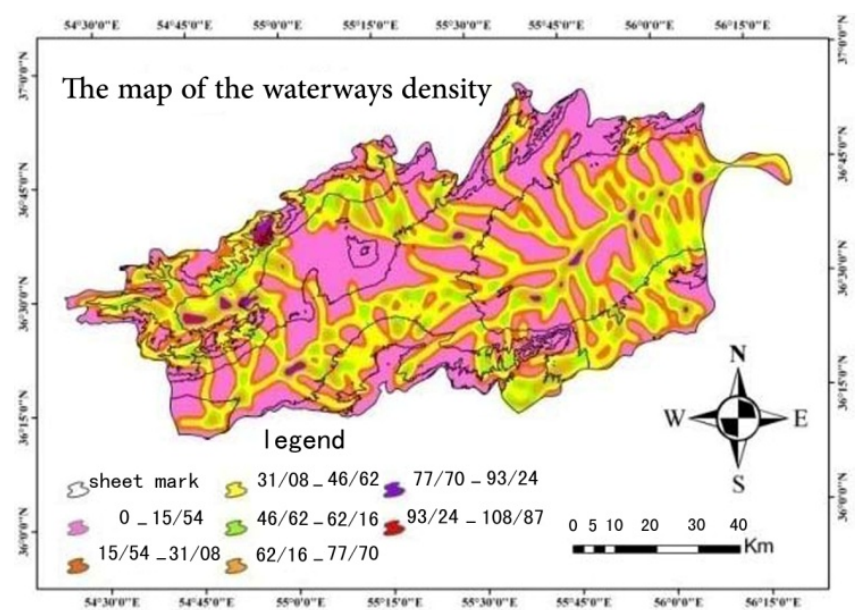

Figure 6. Map of waterways density

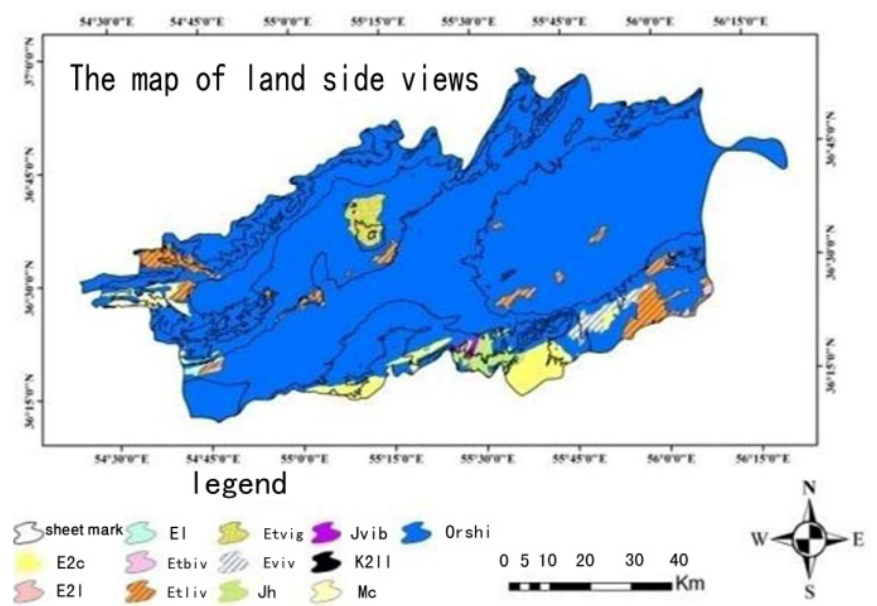

Figure 7. Map of land side views in the studied area

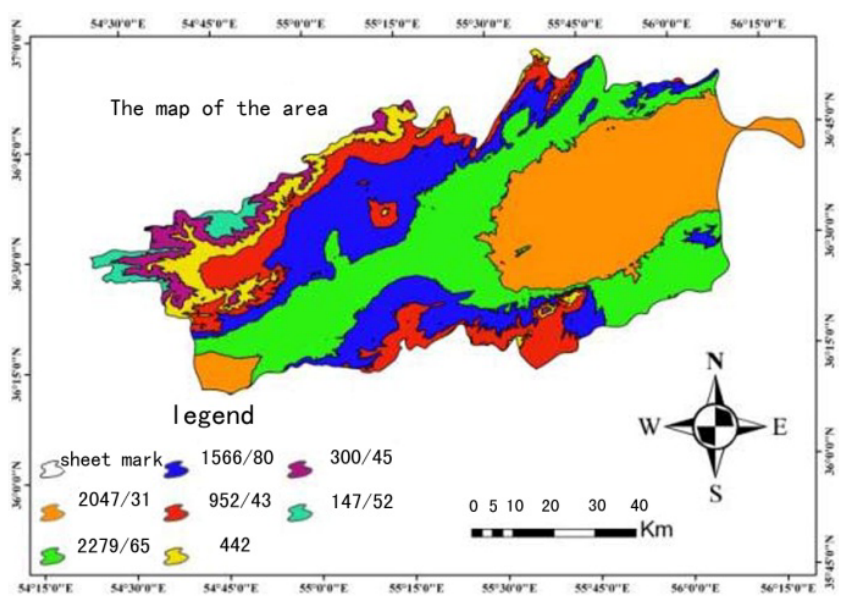

Figure 8. Map of the area of the studied area 


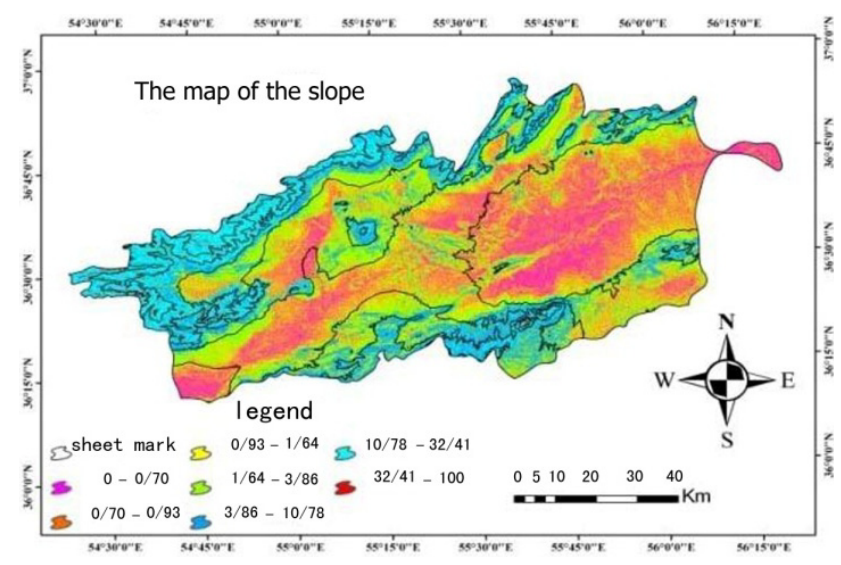

Figure 9. Map of the slope of the studied area

\section{C-Problem solving matrixes in ELECTRE method}

Table 2. Decision matrix (x)

\begin{tabular}{cccccccc}
\hline Areas & Material & Precipitation & $\begin{array}{c}\text { Waterway } \\
\text { density }\end{array}$ & Slope & $\begin{array}{c}\text { Residential } \\
\text { density }\end{array}$ & Altitude & Area \\
\hline 1 & 1 & 115.74 & 51.27 & 2.37 & 3399.55 & 1013 & 2048.31 \\
2 & 5 & 131.18 & 48.24 & 7.86 & 4512.28 & 1261.5 & 2279.65 \\
3 & 9 & 145.65 & 45.43 & 19.48 & 3867.19 & 1496 & 1566.8 \\
4 & 7 & 163.36 & 54.33 & 25.54 & 2489.24 & 1779.5 & 952.43 \\
5 & 5 & 186.67 & 54.39 & 38.62 & 1989.5 & 2154 & 442 \\
6 & 3 & 217.05 & 45.07 & 45.65 & 1316.31 & 2647 & 300.45 \\
7 & 1 & 263.5 & 25.55 & 62.1 & 869.02 & 3405 & 147.52 \\
\hline
\end{tabular}

Table 3. Descaled decision matrix (R)

\begin{tabular}{cccccccc}
\hline Areas & Material & Precipitation & $\begin{array}{c}\text { Waterway } \\
\text { density }\end{array}$ & Slope & $\begin{array}{c}\text { Residential } \\
\text { density }\end{array}$ & Altitude & Area \\
\hline 1 & 0.0724 & 0.2414 & 0.4103 & 0.0257 & 0.4407 & 0.1812 & 0.5668 \\
2 & 0.3618 & 0.2736 & 0.3861 & 0.0851 & 0.5849 & 0.2256 & 0.6308 \\
3 & 0.6512 & 0.3038 & 0.3636 & 0.2119 & 0.5013 & 0.2674 & 0.4335 \\
4 & 0.5065 & 0.34 .7 & 0.4348 & 0.2765 & 0.3227 & 0.3183 & 0.2635 \\
5 & 0.3618 & 0.3893 & 0.4353 & 0.4180 & 0.2579 & 0.3852 & 0.1223 \\
6 & 0.2171 & 0.4527 & 0.3607 & 0.4941 & 0.1706 & 0.4734 & 0.0831 \\
7 & 0.0724 & 0.5698 & 0.2045 & 0.6722 & 0.1126 & 0.6090 & 0.0408 \\
\hline
\end{tabular}

Table 4. Pairwise comparison matrix of different criteria (S)

\begin{tabular}{lcccccccc}
\hline \multicolumn{1}{c}{ Criteria } & $\begin{array}{c}\text { Materi } \\
\text { al }\end{array}$ & $\begin{array}{c}\text { Precipitati } \\
\text { on }\end{array}$ & $\begin{array}{c}\text { Waterway } \\
\text { density }\end{array}$ & $\begin{array}{c}\text { Slop } \\
\text { e }\end{array}$ & $\begin{array}{c}\text { Residential } \\
\text { density }\end{array}$ & $\begin{array}{c}\text { Altitu } \\
\text { de }\end{array}$ & $\begin{array}{c}\text { Are } \\
\text { a }\end{array}$ & $\begin{array}{c}\text { Weight } \\
\text { vector }\end{array}$ \\
\hline Material & 1 & 3 & 5 & 5 & 7 & 7 & 9 & $0 / 3868$ \\
precipitation & 0.33 & 1 & 3 & 5 & 5 & 7 & 7 & 0.2339 \\
$\begin{array}{l}\text { Waterway } \\
\text { density }\end{array}$ & 0.2 & 0.33 & 1 & 3 & 5 & 7 & 7 & 0.1585 \\
\hline
\end{tabular}




\begin{tabular}{lcccccccc}
\hline slope & 0.2 & 0.2 & 0.33 & 1 & 3 & 5 & 7 & 0.1028 \\
Fault density & 0.14 & 0.2 & 0.2 & 0.33 & 1 & 3 & 5 & 0.0603 \\
altitude & 0.14 & 0.14 & 0.14 & 0.2 & 0.33 & 1 & 3 & 0.0353 \\
area & 0.14 & 0.14 & 0.14 & 0.14 & 0.2 & 0.33 & 1 & 0.0214
\end{tabular}

Compatibility rate:0/0252 (because it is less than $0 / 1$, the compatibility of criteria matrix is acceptable)

Table 5. Normalized weighted decision matrix (V)

\begin{tabular}{cccccccc}
\hline Areas & Material & Precipitation & $\begin{array}{c}\text { Waterway } \\
\text { density }\end{array}$ & Slope & $\begin{array}{c}\text { Residential } \\
\text { density }\end{array}$ & Altitude & Area \\
\hline 1 & 0.0278 & 0.567 & 0.0650 & 0.0026 & 0.0267 & 0.0068 & 0.0122 \\
2 & 0.1349 & 0.0643 & 0.0612 & 0.0087 & 0.0354 & 0.0080 & 0.0136 \\
3 & 0.2515 & 0.0714 & 0.0567 & 0.0218 & 0.0303 & 0.0095 & 0.0093 \\
4 & 0.1956 & 0.0800 & 0.0689 & 0.0284 & 0.0194 & 0.0113 & 0.0057 \\
5 & 0.1397 & 0.0915 & 0.0689 & 0.0430 & 0.0156 & 0.0137 & 0.0026 \\
6 & 0.0838 & 0.1063 & 0.0571 & 0.0508 & 0.0103 & 0.0169 & 0.0018 \\
7 & 0.0279 & 0.1291 & 0.0324 & 0.0691 & 0.0068 & 0.0217 & 0.0009 \\
\hline
\end{tabular}

Table 6. Agreement matrix (C)

\begin{tabular}{cccccccc}
\hline Areas & Material & Precipitation & $\begin{array}{c}\text { Waterway } \\
\text { density }\end{array}$ & Slope & $\begin{array}{c}\text { Residential } \\
\text { density }\end{array}$ & Altitude & Area \\
\hline 1 & 0.0000 & 0.1584 & 0.1799 & 0.0820 & 0.0820 & 0.2404 & 0.6266 \\
2 & 0.8415 & 0.0000 & 0.2404 & 0.0820 & 0.4682 & 0.6266 & 0.6266 \\
3 & 0.8200 & 0.7595 & 0.0000 & 0.4682 & 0.4682 & 0.6266 & 0.6266 \\
4 & 0.9179 & 0.9179 & 0.5317 & 0.0000 & 0.4682 & 0.6266 & 0.6266 \\
5 & 0.9179 & 0.9179 & 0.5317 & 0.5317 & 0.0000 & 0.6266 & 0.6266 \\
6 & 0.7595 & 0.3733 & 0.3733 & 0.3733 & 0.3733 & 0.0000 & 0.6266 \\
7 & 0.7595 & 0.3733 & 0.3733 & 0.3733 & 0.3733 & 0.3733 & 0.0000 \\
\hline
\end{tabular}

Table 7. Disagreement matrix (D)

\begin{tabular}{cccccccc}
\hline Areas & Material & Precipitation & $\begin{array}{c}\text { Waterway } \\
\text { density }\end{array}$ & Slope & $\begin{array}{c}\text { Residential } \\
\text { density }\end{array}$ & Altitude & Area \\
\hline 1 & 0 & 1 & 1 & 1 & 1 & 1 & 1 \\
2 & 0.034363 & 0 & 1 & 1 & 1 & 0.752724 & 0.579949 \\
3 & 0.033115 & 0.045258 & 0 & 0.201867 & 0.189562 & 0.208627 & 0.258264 \\
4 & 0.042544 & 0.283766 & 1 & 0 & 0.260421 & 0.23532 & 0.292604 \\
5 & 0.098926 & 0.578001 & 1 & 1 & 0 & 0.266307 & 0.336741 \\
6 & 0.29231 & 1 & 1 & 1 & 1 & 0 & 0407174 \\
7 & 0.450397 & 1 & 1 & 0.1028 & 1 & 1 & 0 \\
\hline
\end{tabular}

Table 8. Agreement dominance matrix (F)

\begin{tabular}{cccccccc}
\hline Areas & Material & Precipitation & Waterway density & Slope & Residential density & Altitude & Area \\
\hline 1 & 0 & 0 & 0 & 0 & 0 & 0 & 1 \\
2 & 1 & 0 & 0 & 0 & 0 & 1 & 1 \\
3 & 1 & 1 & 0 & 0 & 0 & 1 & 1 \\
4 & 1 & 1 & 1 & 0 & 0 & 1 & 1 \\
5 & 1 & 1 & 1 & 1 & 0 & 1 & 1 \\
6 & 1 & 0 & 0 & 0 & 0 & 0 & 1 \\
7 & 1 & 0 & 0 & 0 & 0 & 0 & 0 \\
\hline
\end{tabular}


Table 9. Disagreement dominance matrix (G)

\begin{tabular}{cccccccc}
\hline Areas & Material & Precipitation & $\begin{array}{c}\text { Waterway } \\
\text { density }\end{array}$ & Slope & $\begin{array}{c}\text { Residential } \\
\text { density }\end{array}$ & Altitude & Area \\
\hline 1 & 0 & 0 & 0 & 0 & 0 & 0 & 0 \\
2 & 1 & 0 & 0 & 0 & 0 & 0 & 1 \\
3 & 1 & 1 & 0 & 1 & 1 & 1 & 1 \\
4 & 1 & 1 & 0 & 0 & 1 & 1 & 1 \\
5 & 1 & 1 & 0 & 0 & 0 & 1 & 1 \\
6 & 1 & 0 & 0 & 0 & 0 & 0 & 1 \\
7 & 1 & 0 & 0 & 1 & 0 & 0 & 0 \\
\hline
\end{tabular}

Table 10. Final dominance matrix $(\mathrm{H})$

\begin{tabular}{cccccccc}
\hline Areas & Material & Precipitation & $\begin{array}{c}\text { Waterway } \\
\text { density }\end{array}$ & Slope & $\begin{array}{c}\text { Residential } \\
\text { density }\end{array}$ & Altitude & Area \\
\hline 1 & 0 & 0 & 0 & 0 & 0 & 0 & 0 \\
2 & 1 & 0 & 0 & 0 & 0 & 0 & 1 \\
3 & 1 & 1 & 0 & 0 & 0 & 1 & 1 \\
4 & 1 & 1 & 0 & 0 & 0 & 1 & 1 \\
5 & 1 & 1 & 0 & 0 & 0 & 1 & 1 \\
6 & 1 & 0 & 0 & 0 & 0 & 0 & 1 \\
7 & 1 & 0 & 0 & 0 & 0 & 0 & 0 \\
\hline
\end{tabular}

Table 11. The number of dominance and defeat of each of the selected areas

\begin{tabular}{cccc}
\hline Areas & Number of dominances & Number of defeats & Difference \\
\hline 1 & 0 & 4 & -6 \\
2 & 2 & 4 & -2 \\
3 & 4 & 2 & 2 \\
4 & 4 & 2 & 2 \\
5 & 4 & 2 & 2 \\
6 & 2 & 4 & -2 \\
7 & 1 & 5 & -4 \\
\hline
\end{tabular}

\section{D-Problem solving matrixes in linear assignment method}

Table 12. Decision matrix

\begin{tabular}{cccccccc}
\hline Areas & Material & Precipitation & $\begin{array}{c}\text { Waterway } \\
\text { density }\end{array}$ & Slope & $\begin{array}{c}\text { Residential } \\
\text { density }\end{array}$ & Altitude & Area \\
\hline 1 & 2 & 115.74 & 51.27 & 2.37 & 3399.55 & 1013 & 2048.31 \\
2 & 5 & 131.18 & 48.24 & 7.86 & 4512.28 & 1261.5 & 2279.65 \\
3 & 9 & 145.65 & 45.43 & 19.48 & 3867.19 & 1496 & 1566.8 \\
4 & 7 & 163.36 & 54.33 & 25.54 & 2489.24 & 1779.5 & 952.43 \\
5 & 4 & 186.67 & 54.39 & 38.62 & 1989.5 & 2154 & 442 \\
6 & 3 & 217.05 & 45.07 & 45.65 & 1316.31 & 2647 & 300.45 \\
7 & 1 & 263.5 & 25.55 & 62.1 & 869.02 & 3405 & 147.52 \\
\hline
\end{tabular}


Table 13. Ranking matrix of alternatives based on the criteria

\begin{tabular}{cccccccc}
\hline Ranking & Material & Precipitation & Waterway density & Slope & Residential density & Altitude & Area \\
\hline first & 3 & 7 & 5 & 1 & 2 & 1 & 2 \\
second & 4 & 6 & 4 & 2 & 3 & 2 & 1 \\
third & 2 & 5 & 1 & 3 & 1 & 3 & 3 \\
fourth & 5 & 4 & 2 & 4 & 4 & 4 & 4 \\
fifth & 6 & 3 & 3 & 5 & 5 & 5 & 5 \\
sixth & 1 & 2 & 6 & 6 & 6 & 6 & 6 \\
seventh & 7 & 1 & 7 & 7 & 7 & 7 & 7 \\
\hline
\end{tabular}

Table 14. Weight matrix of the number of ranking alternatives

\begin{tabular}{cccccccc}
\hline Areas & First rank & second rank & third rank & fourth rank & fifth rank & sixth rank & seventh rank \\
\hline 1 & 0.137 & 0.0215 & 0.218 & 0 & 0 & 0.386 & 0.234 \\
2 & 0.082 & 0.1384 & 0.386 & 0.1584 & 0 & 0 & 0 \\
3 & 0.3862 & 0.0605 & 0.1599 & 0 & 0.18189 & 0 & 0 \\
4 & 0 & 0.5446 & 0 & 0.4554 & 0 & 0 & 0 \\
5 & 0.1584 & 0 & 0.2349 & 0.3862 & 0.2204 & 0 & 0 \\
6 & 0 & 0.2349 & 0 & 0 & 0.3862 & 0.23624 & 0 \\
7 & 0.2349 & 0 & 0 & 0 & 0 & 0 & 0.765 \\
\hline
\end{tabular}

Table 15. Alternatives scoring table

\begin{tabular}{clllllll}
\hline $\begin{array}{c}\text { Points } \\
\text { Areas }\end{array}$ & & & & & & \\
\hline 1 & 0 & 0 & 0 & 0 & 0 & 1 & 0 \\
2 & 0 & 0 & 1 & 0 & 0 & 0 & 0 \\
3 & 1 & 0 & 0 & 0 & 0 & 0 & 0 \\
4 & 0 & 1 & 0 & 0 & 0 & 0 & 0 \\
5 & 0 & 0 & 0 & 1 & 0 & 0 & 0 \\
6 & 0 & 0 & 0 & 0 & 1 & 0 & 0 \\
7 & 0 & 0 & 0 & 0 & 0 & 0 & 1 \\
\hline
\end{tabular}

Table 16. Ranking alternatives

\begin{tabular}{cccccccc}
\hline Areas & 1 & 2 & 3 & 3 & 5 & 6 & 7 \\
\hline Rankings & sixth & third & first & second & fourth & fifth & seventh \\
\hline
\end{tabular}

\section{Discussion}

Systematic approach to the geography as a distribution science made geography dependent to mathematics more than ever before (Shokooee, 1998, 43). In general, the model is a schematic but accurate description of the system that apparently is consistent with its past behavior. Therefore, there is hope that this model can be used to predict the future behavior of the system (Hekmatnia and Mousavi, 2006, 29). Decision-making models and optimization of them has always been the focus of attention of mathematicians and industry professionals since the industrial movement in the world, and especially since World War II but their base has been having an assessment criterion (Asayesh and Estelaji, 2003, 41). In recent decades, the attention of researchers is shifting to multi-criteria decision making models for complex decision makings. In these models, instead of using a desirable criteria a number of assessment criteria are used (Taherkhani, 1386, 62). Nowadays, prioritizing and selecting alternatives and appropriate substitutes among various factors and making a decision among them is of great important in environmental planning and management. In other words, in order to achieve better results, using appropriate methods which have the ability to combine multiple criteria seem necessary so that it will become possible to make appropriate preparations and logistics for environmental planning and management. 


\section{Conclusion}

The findings indicate that among the seven zones in ELECTRE method mentioned above, zones $(3,4,5)$ with four dominations and 2 defeats and 2 points are in the first ranking and are the most suitable zones for artificial recharge. Zone (1) with six defeats and no dominations and (-6) points is in the last ranking and is not suitable for artificial recharge of ground water. Zones $(2,6,7)$ respectively with $(2,2,1)$ dominations and $(4,4,5)$ defeats and with $(-2,-2,-4)$ points are in the next rankings respectively. Zones $(1,2,6,7)$ must be removed because the number of their defeats is more than the number of their dominations and have negative points. In linear assignment method, among 7 zones, zone 3 has the first rank and is the best zone for artificial recharge and zone 7 is in the last ranking and is not suitable for artificial recharge. Zones $(4,2,5,6,1)$ are in the next rankings respectively. Between these two methods, the results of linear assignment method are more consistent with reality and are more accurate.

\section{References}

Abdi, P., \& Ghayoomian, J. (2000). Determining appropriate locations for spreading floodwater in Zanjan plain using geophysics data and GIS. Proceedings of the national conference for significant achievements of aquifer project. Pp. 86-99, Tehran, Iran.

Ahmad, S. A., Tewfik, S. R., \& Talaa, H. A. (2002). Development and verification of a decision support system for the selection of optimum water reuse scheme. Desalination, 152, 339-352.

Anand Raj, P. A., \& Kumar, D. N. (1996). Ranking of river basin alternative using ELECTER. Hydrological Science, 41, 326-335.

Asayesh, H., \& Estelaji, A. (2003). Principles and methods of local planning (models, methods, and skills). Islamic Azad University of Shahre Rey Publications, Tehran, Iran

Chen, Y. W. (2001). Implementing hierarchy process by fuzzy integral, International Journal of Fuzzy System, 3.

Despic, O., \& Simonovic, S. P. (2006). Agnation operation for soft decision making in water resource, Fuzzy Sets and System, 15, 11-33.

Dey, P. K., \& Ramcharan, E. K. (2000). Analytic hierarchy process helps select site for limestone quarry expansion in Barbados. Journal of Environmental Management, 2(1).

Freeze, R. A., \& Cherry, J. A. (1979). Groundwater, prentice-Hall, Englewood Cliffs, New Jersey.

Ghodsipoor, H. (2008). Hierarchical analytical process. Fifth edition. Amir Kabir University Press, Tehran, Iran.

Hekmatnia, H., \& Mousavi, M. (2006). Applying models in geography with the focus on urban and local planning. Elme Novin Publications. Yazd, Iran.

Kia-Heyrati, J. (2003). Studying the functioning of floodwater spreading system in recharging ground water aquifers in Moghar Plain in Isfahan. Master thesis of irrigation and drainage. Isfahan University of Technology.

Kowsar, A. (2005). Applying methods for spreading floodwater in artificial recharge of groundwater aquifers. Zeitoon Journal, 46(47), 16-23.

Krishnomurthy, J. N., Kumar, Jayaraman, V., \& Manivel, M. (1996). An Approach to demarcate ground water potential zones thorough remote sensing and a geographical information system, INT. J. Remote Sensing, 17(10), 1867-1884.

Limon, G. A., \& Martinez, Y. (2006). Multi-criteria modeling of irrigation water marked at basin level: A Spanish case study. Eropiangeornal of operational Research, 173, 313-336.

Mianabadi, H., \& Afshar, A. (2007). Fuzzy group decision making and its application in water resource planning and management. Proceedings of Iran Water Resource Management Conference, January 12-13, Isfahan, Iran.

Mianabadi, H., \& Afshar, A. (2008). Multi attribute decision making to rank urban water supply scheme, Water and Watershed Journal, 19(66), 34-45.

Mousavi, S. F., Chitsazan, M., Mirzaee, Y., Shaban, M., \& Mohammadi, H. (2009). Integrating remote control and GIS in order to find potentials for locating appropriate areas for groundwater recharge, Kamestan anticline area. Proceedings of geometrics conference and exhibition, Tehran, Iran.

Noori, B., Ghayoomian, J., Mohseni Sarooi, M., Darvishsefat, A., \& Feiznia, S. (2004). Determining appropriate areas for artificial recharge of groundwater using recharge ponds and GIS. Iran Natural Resources Journal. 
57(3), 635-647.

Olson, D. L. (2004). Comparison of weights in TOPSIS models, Journal of Mathematical and Computer Modeling, 40(7).

Roy, B. (1991). The outranking approach and the foundation of ELECTRE methods, Theory and Decision, 31, 49-73.

Saaty, T. L. (1986). Axiomatic foundation of analytical hierarchy process. Management Science, 31(7), 1986.

Saaty, T. L. (1994). Highlights and critical points in the theory and application of the analytical hierarchy process, European Journal of operational research, 74, 426-447.

Saaty, T. L. (2000). Decision Making for Leaders: The Analytical Hierarchy Process for Decisions in a Complex World, RWS Publications, 4922 Ellsworth Ave., Pittsburgh, PA 15213.

Saaty, T. L. (2001). Fundamentals of the analytic hierarchy process, "The Analytic Hierarchy Process in Natural Resource and Environmental Decision Making”, D. L. Schmoldt, J. Kangas, G. A. Mendoza and M Pesonen, (eds.), Kluwer Academic Publishers, pp. 15-36.

Saaty, T. L. (2004). The Analytic Hierarchy and Analytic Network Processes for the Measurement of Intangibles and for Decision-Making, in Multiple Criteria Decision Analysis: The State of the Art Surveys, edited by Figueira, J., Greco, S. and Ehrgott, M., Kluwer Academic Publishers, Dordrecht, pp. 346-408.

Saraf, A. K., \& Choudhury, P. R. (1998). Integrated remote sensing and GIS for ground water exploration and identification of artificial recharge sites, INT.J. Remote Sensing, 19(10), 1825-1841.

Sedaghat, M. (2008). Earth and water resources. Payam Noor Publications, Tehran, Iran.

Shokooee, H. (1998). New perspectives to urban geography. Samt Publications, Tehran, Iran.

Tavakoli, A., \& Aliahmadi, A. (2005). The selection and prioritizing method for methods of technology transference. Science and Industry University Publications, Tehran, Iran.

Tille, M., \& Dumont, A. G. (2003). Methods of multi-criteria decision analysis within the road project like an element of the sustainability, 3rd Swiss Transport Research Conference, March 19-21, 2003. Switzerland.

Vami, B. (1992). Proiect opportunity study on integrated use of the RazgahNepheline ores, Iran by metallurgical processing into alumina cement, sodium carbonate and potash, Final Report, General Explanatory Note, Tehran, Iran.

\section{Copyrights}

Copyright for this article is retained by the author(s), with first publication rights granted to the journal.

This is an open-access article distributed under the terms and conditions of the Creative Commons Attribution license (http://creativecommons.org/licenses/by/3.0/). 